J. Dairy Sci. 98:2701-2712

http://dx.doi.org/10.3168/jds.2014-8132

(C) American Dairy Science Association ${ }^{\circledR}, 2015$.

\title{
On the analysis of Canadian Holstein dairy cow lactation curves using standard growth functions
}

\author{
S. López, ${ }^{\star 1}$ J. France,† N. E. Odongo,† R. A. McBride,† E. Kebreab,† O. AlZahal,† B. W. McBride,† \\ and J. Dijkstra§ \\ *Instituto de Ganadería de Montaña (CSIC-ULE), Departamento de Producción Animal, Universidad de León, 24071 León, Spain \\ †Department of Animal and Poultry Science, University of Guelph, Guelph, Ontario N1G 2W1, Canada \\ ‡Department of Animal Science, University of California, Davis 95616 \\ §Animal Nutrition Group, Wageningen Institute of Animal Sciences, Wageningen University, Marijkeweg 40, 6709 PG Wageningen, \\ the Netherlands
}

\section{ABSTRACT}

Six classical growth functions (monomolecular, Schumacher, Gompertz, logistic, Richards, and Morgan) were fitted to individual and average (by parity) cumulative milk production curves of Canadian Holstein dairy cows. The data analyzed consisted of approximately 91,000 daily milk yield records corresponding to 122 first, 99 second, and 92 third parity individual lactation curves. The functions were fitted using nonlinear regression procedures, and their performance was assessed using goodness-of-fit statistics (coefficient of determination, residual mean squares, Akaike information criterion, and the correlation and concordance coefficients between observed and adjusted milk yields at several days in milk). Overall, all the growth functions evaluated showed an acceptable fit to the cumulative milk production curves, with the Richards equation ranking first (smallest Akaike information criterion) followed by the Morgan equation. Differences among the functions in their goodness-of-fit were enlarged when fitted to average curves by parity, where the sigmoidal functions with a variable point of inflection (Richards and Morgan) outperformed the other 4 equations. All the functions provided satisfactory predictions of milk yield (calculated from the first derivative of the functions) at different lactation stages, from early to late lactation. The Richards and Morgan equations provided the most accurate estimates of peak yield and total milk production per 305-d lactation, whereas the least accurate estimates were obtained with the logistic equation. In conclusion, classical growth functions (especially sigmoidal functions with a variable point of inflection) proved to be feasible alternatives to fit cumulative milk production curves of

Received March 13, 2014.

Accepted December 7, 2014.

${ }^{1}$ Corresponding author: s.lopez@unileon.es dairy cows, resulting in suitable statistical performance and accurate estimates of lactation traits.

Key words: dairy cow, growth function, lactation curve, lactation trait

\section{INTRODUCTION}

A typical lactation curve increases rapidly from initial yield at calving to a peak then decreases gradually as lactation progresses. Several models with different functional forms have been proposed to represent daily milk yield versus time of lactation in dairy cows (e.g., Wood, 1967; Dijkstra et al., 1997; Pollott, 2000; López, 2008). Variations in the shape and form of the lactation curve stem from factors including genetic background, parity, diet, and other environmental influences (Wood, 1968, 1970, 1980). The models used to describe milk yield can be divided into 2 groups: mechanistic models, based on the biology of lactation aiming to describe the causative mechanisms underlying a specific shape (e.g., Dijkstra et al., 1997; Pollott, 2000), and empirical models, based on the mathematical representation of actual milk yield data and simply trying to describe the shape (e.g., Wood, 1967; Rook et al., 1993; Grossman et al., 1999). The choice of model is a balance between fitting properties and requirements for biological interpretation. For example, detailed mechanistic models (Pollott, 2000) have the advantage of parameters with biological interpretation, but can be difficult to fit and may give rise to parameter estimates showing large standard errors and multicollinearity. Conversely, more simple empirical models can rapidly converge to an acceptable solution and provide adequate fits to data, but lack a biological basis. A simple mechanistic model, such as the one proposed by Dijkstra et al. (1997), may provide such a balance between fitting properties and biological interpretation (Val-Arreola et al., 2004; Dematawewa et al., 2007).

Knowledge of the shape of the lactation curve is valuable in a management context, especially for decisions 
that are time-dependent. Modelers seek to find parametric descriptors of the shape of the lactation curve to predict characteristics including peak milk yield, time to peak, and persistency. For example, knowing when peak milk yield will occur can assist dairy farmers or managers in planning feeding strategies to maintain peak yield for as long as possible. Also, the persistency of milk yield is an important aspect of total yield. A cow with a flatter lactation curve compared with another cow with the same total 305-d milk production may experience less stress and have a higher feed efficiency (Grossman et al., 1999). Fathi-Nasri et al. (2008) reported the potential of the differentials of simple growth functions as equations for fitting monthly milk records of Holstein dairy cattle. Sigmoidal growth functions have been frequently applied to study somatic growth and population dynamics (Thornley and France, 2007; López, 2008). The shape of the cumulative milk production curve is similar to that of a growth curve; thus, various growth functions may be used to model the curve.

The cumulative milk production curve shows a smoother trajectory than that of the conventional lactation curve. It would be affected to a lesser extent if a few (sporadic) records are missing, and is less sensitive to the occurrence of outliers or abnormal recordings. Disturbances in the lactation curve can be highly influential when fitting classical lactation models, whereas the fit of cumulative milk production curves would be little affected by the occurrence of such occasional deviations. Furthermore, the lactation curve (daily milk yield vs. DIM) does not always follow the typical trajectory (standard curve), and other curve shapes have been observed. Nonstandard lactation curve shapes are not always easily fitted by conventional lactation models (Rekik and Gara, 2004; Macciotta et al., 2005; Silvestre et al., 2009). Regardless of the shape of the lactation curve, the cumulative milk production curve will always follow a monotonically increasing pattern that can be fitted using growth functions to represent the underlying trend of the lactation curve relating to the productive potential of the cow. The purpose of the current work was to investigate the suitability of 6 standard growth functions in describing the 305-d lactation curve of Holstein dairy cows from cumulative milk production data calculated from daily individual cow milking records.

\section{MATERIALS AND METHODS}

\section{Data}

The data analyzed consisted of approximately 91,000 daily milk yield records, corresponding to 122 first, 99 second, and 92 third parity individual lactation curves (for a total of 313 curves) of Holstein dairy cows collected at the Elora Dairy Research Centre (University of Guelph). Lactation length varied from 180 to 575 $\mathrm{d}$, but longer lactations were truncated to $305 \mathrm{~d}$ for this analysis. Most of the curves $(187 / 313)$ were up to $305 \mathrm{~d}$, and only 20 curves (17 of them for third parity) corresponded to lactations of less than $250 \mathrm{~d}$. In all cases milk yield was recorded daily. The database contained cow records of birth date, calving date, lactation number (parity), milking date, and daily milk yield. Cumulative milk production was calculated from daily milk yield records. The cows were fed 60:40 forage-toconcentrate as a TMR composed (per kilogram of DM) of $332 \mathrm{~g}$ of corn silage, $221 \mathrm{~g}$ of alfalfa silage, $55 \mathrm{~g}$ of hay, $202 \mathrm{~g}$ of high-moisture corn, and $189 \mathrm{~g}$ of custom supplement, formulated to meet NRC (2001) requirements for a lactating dairy cow. All cows were fed and milked twice daily (feeding at 0700 and 1300 h; milking at 0500 and $1500 \mathrm{~h}$ ).

\section{Model Fitting}

Cumulative milk production generally follows a curvilinear trend that closely resembles the trend of a classical somatic growth curve (Figure 1). The 6 equations presented in Table 1, and usually fitted to growth curves, were used to describe the cumulative lactation curves. The first equation is the simple exponential function proposed by Mitscherlich (1909), often referred to as the Mitscherlich or monomolecular equation, and has no point of inflection, thus representing only a diminishing returns (nonsigmoidal) pattern. The Schumacher, Gompertz, and logistic equations are 3-parameter sigmoidal functions each with a fixed point of inflection occurring when cumulative production reaches a certain proportion of the upper asymptote, the asymptotic cumulative milk production as DIM tend to infinity $\left(\boldsymbol{y}_{f}\right)$, namely at $\frac{y_{f}}{\mathrm{e}^{2}}, \frac{y_{f}}{e}$, and $\frac{y_{f}}{2}$, respectively. The Richards and Morgan equations have an extra parameter (shape constant $n$ ) and can be considered flexible functions which represent diminishing returns or sigmoidal profiles (the Richards equation is sigmoidal if $n$ $>-1$, and the Morgan equation if $n>1$ ) with a point of inflection at any $y$-value. The 4-parameter Richards equation encompasses the monomolecular, Gompertz, and logistic equations when $n$ has a value of $-1,0$, and 1 , respectively. In the models described, $y(t)$ is cumulative milk production $(\mathrm{kg}), t$ is time of lactation or DIM, and $y_{0}, y_{f}, t_{0}, t_{h}, k, D, n$ (all $>0$ except $n \geq-1$ in the case of Richards) are parameters that define the scale and shape of the curves, whereas $y^{\prime}(t)=\mathrm{d} y / \mathrm{d} t$ is the daily 


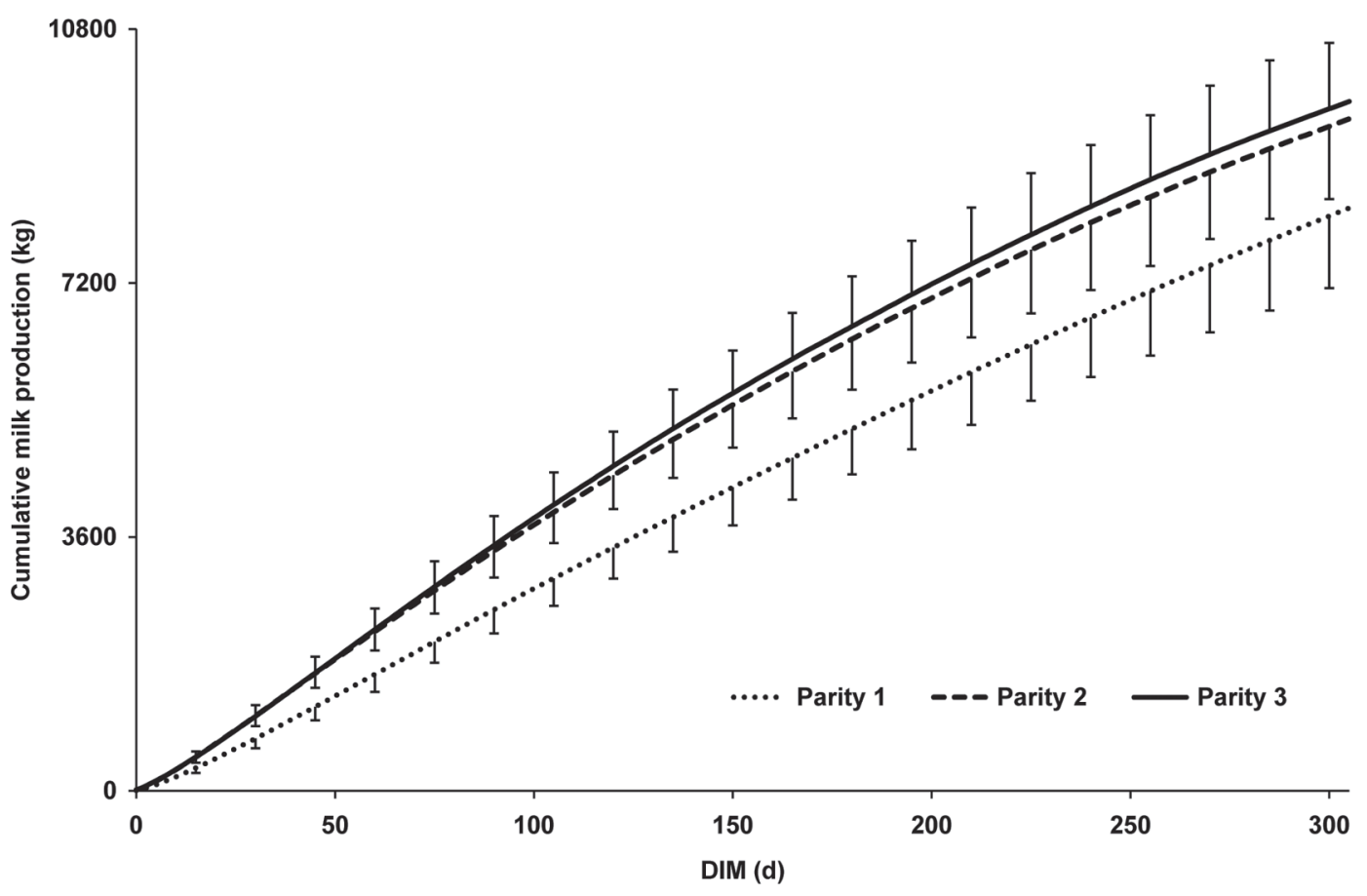

Figure 1. Cumulative milk production curves of Holstein dairy cows (average curves for first, second, and third parity lactations; error bars represent the SD).

milk yield $(\mathrm{kg} / \mathrm{d})$. For more details, refer to Chapter 5 of Thornley and France (2007). Calculations of measures of performance [i.e., time to peak yield $\left(\boldsymbol{t}^{*}, \mathrm{~d}\right)$, peak yield $\left(\boldsymbol{d} \boldsymbol{m} \boldsymbol{y}^{*}, \mathrm{~kg} / \mathrm{d}\right)$, cumulative 305 -d production $\left(\boldsymbol{y}_{305}, \mathrm{~kg}\right)$, and persistency $\left.(\boldsymbol{p}, \% / \mathrm{d})\right]$ are as shown in Table 1.

The candidate functions were fitted to individual-cow cumulative milk production curves for each lactation using the PROC NLIN procedures of SAS (v. 9.13; SAS Inst. Inc., Cary, NC). The Akaike information criterion (AIC; Akaike, 1969) was chosen for comparing models based on goodness-of-fit. A smaller numerical value of AIC indicates a better fit when comparing models (Burnham and Anderson, 2002; Motulsky and Christopoulos, 2003). The behavior of each model across all the lactation curves fitted was evaluated from the mean AIC, the average and median ranking (for each lactation curve, rank $=1$ corresponds to the model with the smallest AIC and rank $=6$ to the one with the greatest AIC), and the number of curves for which the model had the smallest or the greatest AIC (compared with the other models included in the analysis).

Models were also compared based on estimates of model parameters or lactation traits obtained with each equation. Daily milk yield $(\mathrm{kg} / \mathrm{d})$ at several lactation times $(2,70,140,210$, and 280 DIM) were calculated for each individual curve, and then values obtained with each model were compared with the corresponding observed recordings at the same DIM. For the assessment of model performance, correlation between observed and calculated values within each DIM across all individual lactation curves was examined using the Pearson correlation coefficient (PROC CORR of SAS) and the concordance correlation coefficient. Concordance correlation coefficient (CCC) or reproducibility index (Lin, 1989) results from the product of 2 components: the correlation coefficient that measures precision and the bias correction factor $\left(C_{b}\right)$ that assesses model accuracy. If $C_{b}$ equals 1 , this indicates that no deviation from a line of unity has occurred. The product of the 2 values gives simultaneously both the precision and accuracy of the estimation of actual or observed values.

Finally, average cumulative milk production curves were obtained for each parity (Figure 1). Within each parity, all individual milk recordings at each DIM were averaged (Figure 2) and then cumulative milk production was determined. For these average curves, cumulative production after $305 \mathrm{~d}$ of lactation $\left(y_{305}\right)$ was then calculated. The DIM at which peak is reached $\left(t^{*}, \mathrm{~d}\right)$ and daily milk yield at $t^{*}\left(d m y^{*}, \mathrm{~kg} / \mathrm{d}\right)$ were determined for each average curve by selecting the 6 actual data points clustered around peak period with the highest daily milk yields, and then averaging daily milk yield and DIM for those 6 values. The Wood equation 
Table 1. Growth functions used to describe lactation curves, where $y(t)=$ cumulative milk production $(\mathrm{kg}), y^{\prime}(t)=\mathrm{daily}$ yield $(\mathrm{kg} / \mathrm{d}), t=\mathrm{days}$ in milk, and $y_{0}\left(\mathrm{~kg}\right.$ of milk), $y_{f}\left(\mathrm{~kg}\right.$ of milk), $t_{0}(\mathrm{~d}), t_{h}(\mathrm{~d}), k\left(\mathrm{~d}^{-1}\right), D\left(\mathrm{~d}^{-1}\right)$, and $n$ (dimensionless) are parameters (all $>0$ unless otherwise stated) that define the scale and shape of the curves ${ }^{1}$

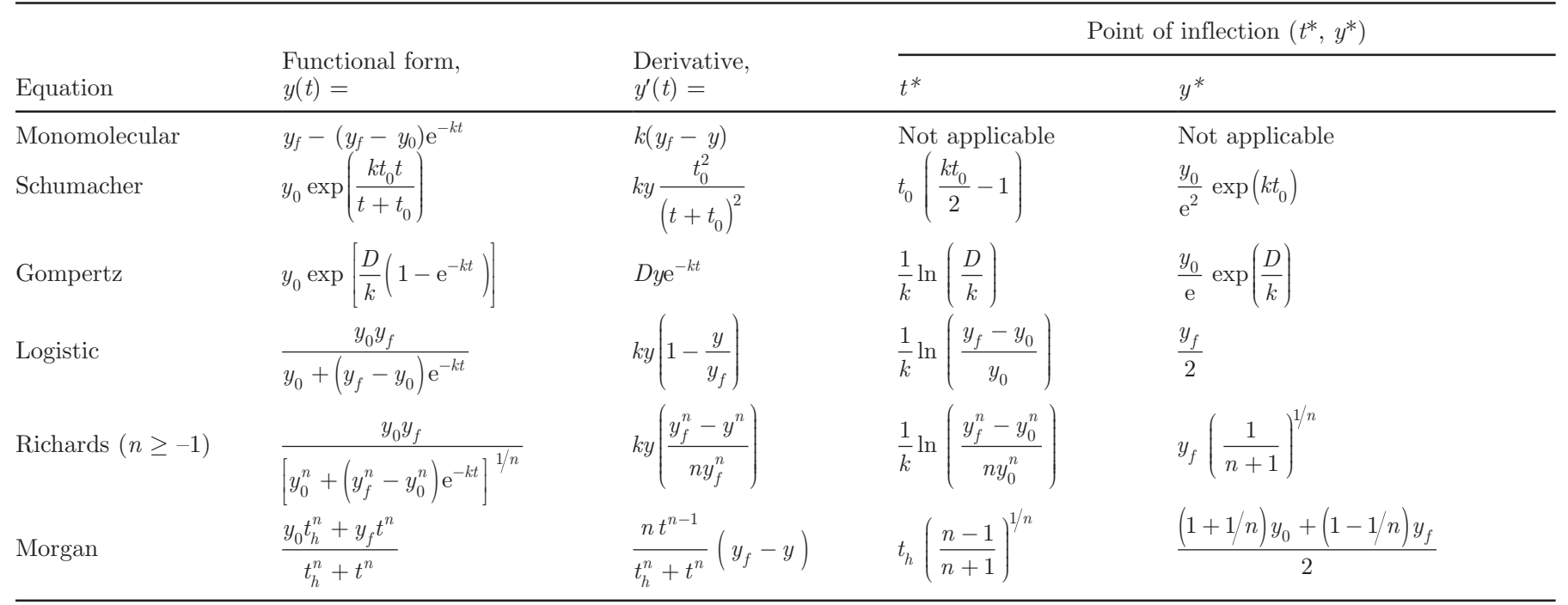

${ }^{1}$ Calculation of performance measures: Time to peak yield is $t^{*}(\mathrm{~d})$, and peak yield, $d m y^{*}(\mathrm{~kg} / \mathrm{d})$, equals $y^{\prime}\left(t=t^{*}\right)$. Cumulative 305 -d production, $y_{305}(\mathrm{~kg})$, is given by $y_{305}=y(t=305)$. A measure of persistency, $p$ (per day), is given by $p=\left(\frac{y_{305}-y^{*}}{305-t^{*}}\right) / y\left(t=\frac{t^{*}+305}{2}\right)$ (it has to be assumed that $t^{*}=0$ for the monomolecular).

was fitted to average lactation curves (daily milk yield vs. DIM), whereas the growth functions were fitted to the average cumulative milk production curves. Values of $y_{305}, t^{*}$, and $d m y^{*}$ calculated for each parity from the average curves were compared with those estimated when fitting each candidate function to evaluate model performance. Statistical goodness-of-fit of the models fitted to the average curves was assessed based on the comparison between observed and fitted daily milk yield values at each DIM, using AIC, residual mean prediction error (Bibby and Toutenburg, 1977), and concordance correlation coefficient.

\section{RESULTS}

In general, all the growth functions provided acceptable fits and described the lactation data adequately, but some differences among functions were noted. Overall, the Richards equation ranked first in terms of goodness-of-fit (smallest AIC), followed by the Morgan equation (Table 2). The Gompertz ranked third, the monomolecular fourth, and the logistic fifth. The Schumacher equation gave the worst goodness-of-fit of the 6 functions tested.

All the functions (except the monomolecular) tended to underestimate milk yields in early $(\mathrm{DIM}=2 \mathrm{~d})$ and late stages of lactation (DIM $=280 \mathrm{~d})$, and to overesti- mate them in midlactation (DIM $=140 \mathrm{~d}$; Table 3$)$. This trend was more noticeable for the Schumacher and logistic equations, with large deviations between observed and estimated values (Table 3). However, the Morgan and Richards equations gave a close fit to the observed values at all lactation stages. As result of its particular behavior (a nonsigmoidal diminishing returns pattern), the monomolecular led to a large overestimation of milk yield after calving, a slight underestimation in midlactation, and some overestimation at late stages of lactation. Estimates of total milk production over a 305-d lactation $\left(y_{305}\right)$ were similar with the monomolecular, Richards, and Morgan equations, with the Gompertz and logistic providing greater values and Schumacher noticeably smaller estimates. Overall, the Morgan, Richards, and monomolecular equations provided close estimates of total milk production for a 305-d lactation, with strong correlation $(\mathrm{r}>0.97)$ and concordance $(\mathrm{CCC}>0.97)$ between observed and predicted values across all the lactation curves considered in the study (Table 3). The Schumacher equation underestimated $y_{305}$ by $7 \%$, whereas the Gompertz overestimated this trait by $8 \%$, although correlation $(\mathrm{r}>0.95)$ and concordance $(\mathrm{CCC}>0.84)$ between observed and predicted values were high in both cases. The logistic equation overestimated $y_{305}$ by $14 \%$ and CCC between observed and predicted values was weaker $(\mathrm{CCC}=0.57)$ than with the other functions. 
Table 2. Model goodness-of-fit based on Akaike information criterion (AIC)

\begin{tabular}{|c|c|c|c|c|c|c|}
\hline Item & Monomolecular & Schumacher & Gompertz & Logistic & Richards & Morgan \\
\hline SE & 24.5 & 31.5 & 24.9 & 24.9 & 30.8 & 25.4 \\
\hline Minimum & 1,608 & 1,210 & 1,597 & 1,718 & 1,175 & 1,419 \\
\hline Median & 3,741 & 4,026 & 3,680 & 3,909 & 3,327 & 3,515 \\
\hline Average ranking & 3.81 & 5.36 & 3.32 & 5.13 & 1.31 & 2.07 \\
\hline Standard error of rankings & 0.061 & 0.055 & 0.053 & 0.041 & 0.039 & 0.036 \\
\hline Number of curves with largest AIC & 24 & 183 & 1 & 104 & 1 & 0 \\
\hline
\end{tabular}

Average values (across all the lactation curves) of parameter estimates $\left(y_{f}, y_{0}\right)$ and performance measures $\left(t^{*}, y^{*}, d m y^{*}, p\right)$ for the different growth functions are summarized in Table 4. Only the Schumacher equation gave acceptable estimates of $y_{0}$ (milk yield at calving), whereas the monomolecular underestimated $y_{0}$ (resulting in $y_{0}=0$ for most of the lactation curves) and all the other functions gave unrealistic overestimates of this parameter (especially the Gompertz and logistic). Large differences were noted among functions in the prediction of DIM to peak yield $\left(t^{*}\right)$, which ranged (average values) from 70.2 (Richards) to $126.0 \mathrm{~d}$ (logistic; Table 4). These discrepancies underscore the importance of how peak yield is determined. Consequently, there were also substantial differences among functions in estimates of $d m y^{*}$ (daily milk yield at peak), with the Gompertz, Richards, and Morgan equations resulting in similar values, whereas Schumacher and logistic gave greater values. Persistency values were greatest when estimated with the monomolecular, and smallest when estimated with the Gompertz and especially with the logistic, with the other 3 functions providing intermediate values.

Correlation coefficients between $d m y^{*}$ and $p$, between $y_{305}$ and $p$, and between $t^{*}$ and $y_{305}$ were low $(-0.4<\mathrm{r}<$ 0.1 ; Table 5) regardless of the function used to estimate these traits. Medium correlation was observed between $t^{*}$ and $d m y^{*}$ (Table 5), negative (increased $d m y^{*}$ as $t^{*}$ occurs earlier) when these were calculated from parameter values obtained with the Schumacher, Gompertz,

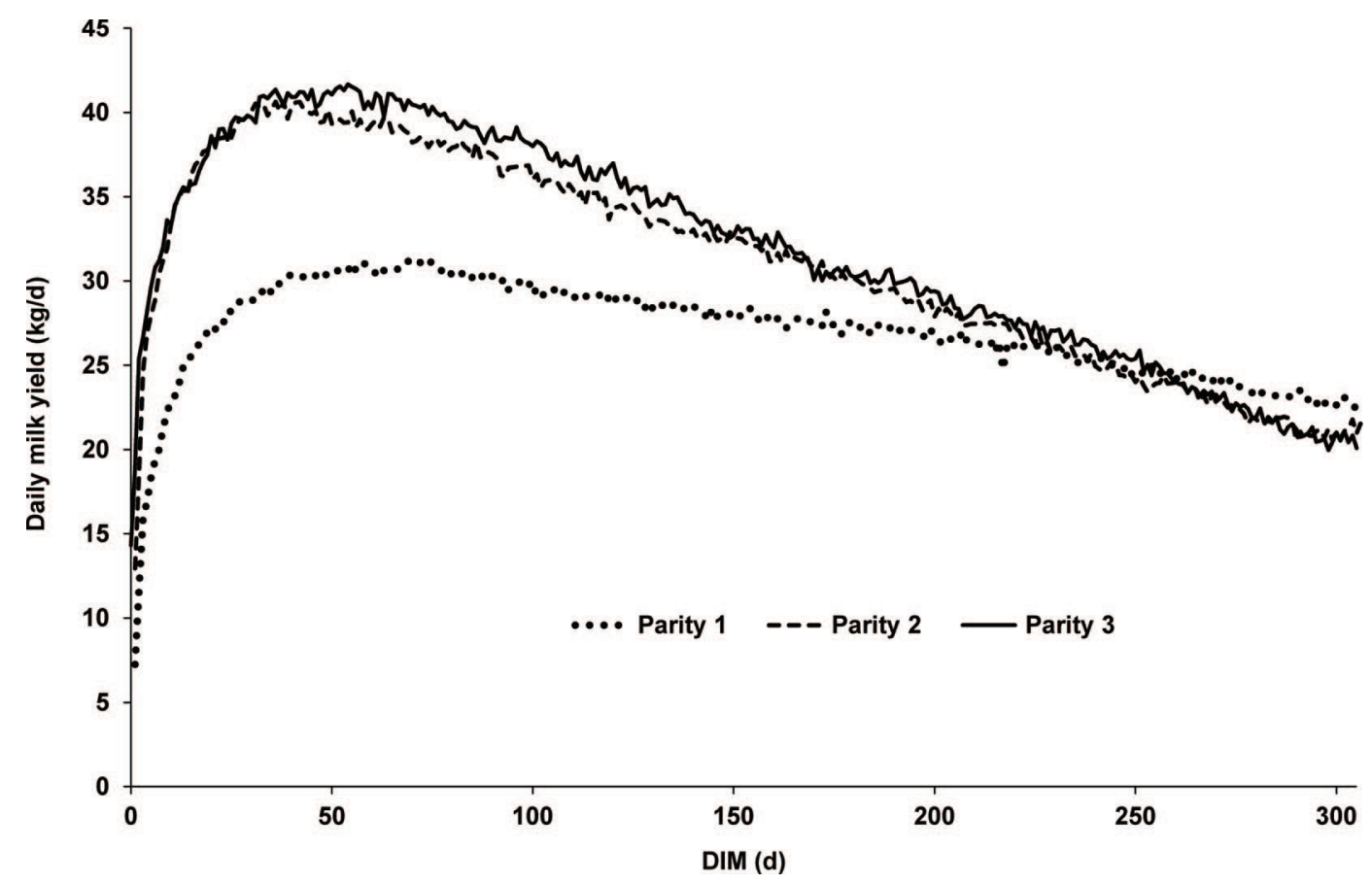

Figure 2. Daily milk yield curves of Holstein dairy cows (average curves for first, second, and third parity lactations). 
Table 3. Model performance: comparison between observed values of daily milk yield ( $\mathrm{kg} / \mathrm{d})$ at 2, 70, 140, 210, and 280 DIM and of cumulative lactation (305 d) milk production $(\mathrm{kg})$ and values estimated by each model (values derived from all the individual lactation curves used in the study)

\begin{tabular}{|c|c|c|c|c|c|c|c|c|}
\hline Milk yield & & $\begin{array}{l}\text { Observed } \\
\text { value }\end{array}$ & Monomolecular & Schumacher & Gompertz & Logistic & Richards & Morgan \\
\hline \multirow[t]{4}{*}{2 DIM } & Mean & 22.0 & 41.1 & 4.0 & 21.8 & 20.6 & 19.8 & 12.3 \\
\hline & SD & 6.9 & 7.3 & 4.3 & 5.1 & 4.3 & 8.0 & 6.1 \\
\hline & Correlation & & 0.743 & 0.236 & 0.582 & 0.462 & 0.520 & 0.498 \\
\hline & Concordance & & 0.162 & 0.036 & 0.555 & 0.403 & 0.493 & 0.233 \\
\hline \multirow[t]{4}{*}{70 DIM } & Mean & 36.7 & 35.5 & 41.5 & 34.5 & 32.5 & 36.0 & 36.7 \\
\hline & SD & 6.9 & 5.6 & 8.0 & 6.3 & 5.8 & 6.4 & 6.4 \\
\hline & Correlation & & 0.893 & 0.886 & 0.875 & 0.808 & 0.896 & 0.893 \\
\hline & Concordance & & 0.856 & 0.725 & 0.825 & 0.652 & 0.889 & 0.890 \\
\hline \multirow[t]{4}{*}{140 DIM } & Mean & 31.7 & 30.7 & 34.1 & 34.5 & 35.9 & 32.6 & 32.9 \\
\hline & SD & 6.0 & 4.4 & 5.3 & 5.5 & 6.3 & 5.0 & 4.9 \\
\hline & Correlation & & 0.781 & 0.762 & 0.779 & 0.789 & 0.799 & 0.805 \\
\hline & Concordance & & 0.735 & 0.691 & 0.694 & 0.637 & 0.774 & 0.769 \\
\hline \multirow[t]{4}{*}{210 DIM } & Mean & 27.9 & 26.8 & 24.6 & 27.0 & 27.2 & 27.1 & 26.6 \\
\hline & SD & 4.9 & 3.9 & 3.8 & 4.7 & 5.1 & 4.2 & 4.2 \\
\hline & Correlation & & 0.796 & 0.802 & 0.786 & 0.786 & 0.817 & 0.826 \\
\hline & Concordance & & 0.753 & 0.606 & 0.771 & 0.778 & 0.795 & 0.789 \\
\hline \multirow[t]{4}{*}{280 DIM } & Mean & 23.1 & 23.6 & 18.2 & 19.3 & 16.5 & 22.0 & 21.5 \\
\hline & SD & 5.92 & 3.48 & 2.71 & 3.91 & 4.62 & 3.60 & 3.59 \\
\hline & Correlation & & 0.615 & 0.673 & 0.744 & 0.567 & 0.727 & 0.715 \\
\hline & Concordance & & 0.536 & 0.322 & 0.530 & 0.307 & 0.630 & 0.599 \\
\hline \multirow{4}{*}{ Cumulative milk production at $305 \mathrm{~d}$ of lactation } & Mean & 9,254 & 9,357 & 8,636 & 9,993 & 10,517 & 9,203 & 9,098 \\
\hline & SD & 1,320 & 1,307 & 1,296 & 1,534 & 1,362 & 1,329 & 1,316 \\
\hline & Correlation & & 0.989 & 0.975 & 0.959 & 0.823 & 0.978 & 0.995 \\
\hline & Concordance & & 0.986 & 0.877 & 0.836 & 0.571 & 0.977 & 0.988 \\
\hline
\end{tabular}


MODELING DAIRY COW LACTATION CURVES

Table 4. Lactation parameters and traits estimated by each equation (values derived from all the individual lactation curves used in the study)

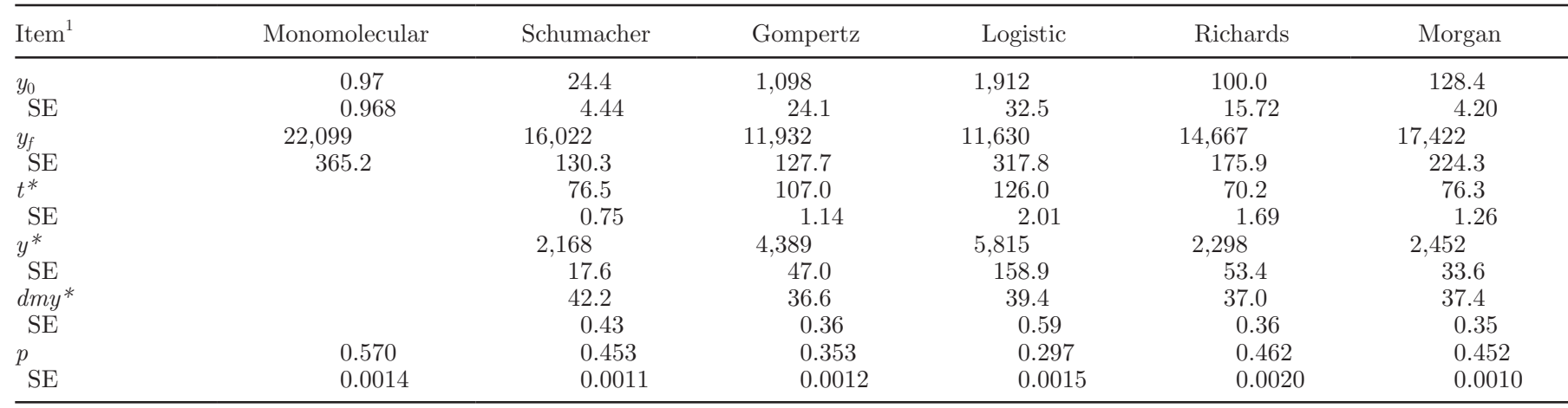

${ }^{1} y_{0}=$ initial milk yield at DIM $=0(\mathrm{~kg}) ; y_{\mathrm{f}}=$ asymptotic cumulative milk production $(\mathrm{kg}) ; t^{*}=$ day in milk at which peak is reached $(\mathrm{d}) ; y^{*}=$ cumulative milk production $(\mathrm{kg})$ at $t^{*} ; d m y^{*}=$ daily milk yield $(\mathrm{kg} / \mathrm{d})$ at $t^{*} ; p=$ persistency index $(\% / \mathrm{d}) ; \mathrm{SE}=$ standard error across all the lactation curves recorded.

Richards, and Morgan equations, and positive when the traits were calculated using the logistic. A strong and positive correlation was observed between $d m y^{*}$ and $y_{305}$ calculated with all functions except for the logistic, where the correlation was medium $(r=0.4)$. There was a strong and positive correlation between $t^{*}$ and $p$ (greater persistency if $t^{*}$ occurred later) when the traits were estimated using sigmoidal functions with a fixed point of inflection (Schumacher, Gompertz, and logistic). This correlation was medium and negative when the Richards equation was used to estimate $t^{*}$ and $p$, and the traits were not correlated when they were estimated with the Morgan equation.

The goodness-of-fit to average lactation curves was best when sigmoidal functions with a variable point of inflection (Richards and Morgan) were used (Table 6). Both functions were superior to the others tested and provided a fit to the daily milk yield data comparing favorably with that achieved when the classical Wood equation was fitted to average lactation curves (Table $6)$.

Wood, Richards, and Morgan equations also provided the closest estimates of $y_{305}$ and $t^{*}$ (compared with the observed values for each parity). The sigmoidal functions with a fixed point of inflection tended to overestimate $t^{*}$ and underestimate $y_{305}$, the deviations between observed and predicted values being largest with the logistic and smallest with the Schumacher (Table 7). The monomolecular tended to overestimate $y_{305}$. All functions (except the monomolecular, from which this trait cannot be calculated) provided close estimates of $d m y^{*}$ (deviations of $\pm 1.1 \mathrm{~kg} / \mathrm{d}$ in parities 1 and 3 , and $-1.6 \mathrm{~kg} / \mathrm{d}$ in parity $2)$, although with the logistic $d m y^{*}$ was slightly overestimated $(3.1 \mathrm{~kg} / \mathrm{d})$ in parity 1 (Table 7 ).

The comparison among parities was generally similar for all the functions fitted and conformed to that seen with the observed values (Table 7 ). Thus, total milk production in a 305 -d lactation $\left(y_{305}\right)$ increased consistently from parity 1 to 3 . Milk yield at peak $\left(d m y^{*}\right)$ also increased from parity 1 to 2 , with a small further increase of approximately $1 \mathrm{~kg} / \mathrm{d}$ from parity 2 to 3 . This was the trend with the observed values and with those predicted by all the functions. As for DIM to peak $\left(t^{*}\right)$, it occurred at a later time in parity 1 (d 68), and earlier in parity 2 (d 37), and at an intermediate time in parity 3 (d 54). This trend was best represented by the Wood, Richards, and Morgan equations, whereas no differences between parities 2 and 3 were observed in the estimate of $t^{*}$ with the other functions.

\section{DISCUSSION}

The typical lactation curve (daily milk yield vs. DIM) comprises 2 differentiable sections: an ascending phase

Table 5. Correlation coefficients between lactation traits estimated by each equation (pooling all values recorded for 3 parities) ${ }^{1}$

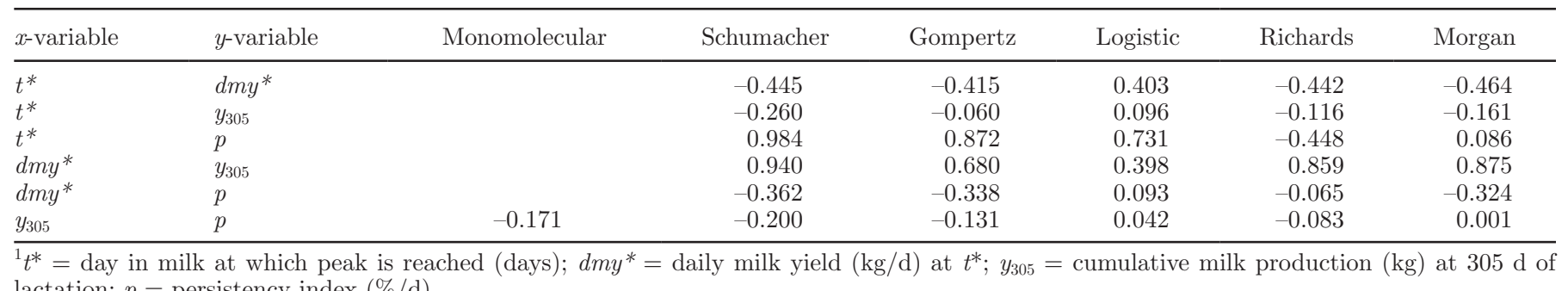
lactation; $p=$ persistency index $(\% / \mathrm{d})$. 
Table 6. Model performance (comparison between observed and fitted daily milk yield values at each DIM) when fitted to average lactation curves for each parity

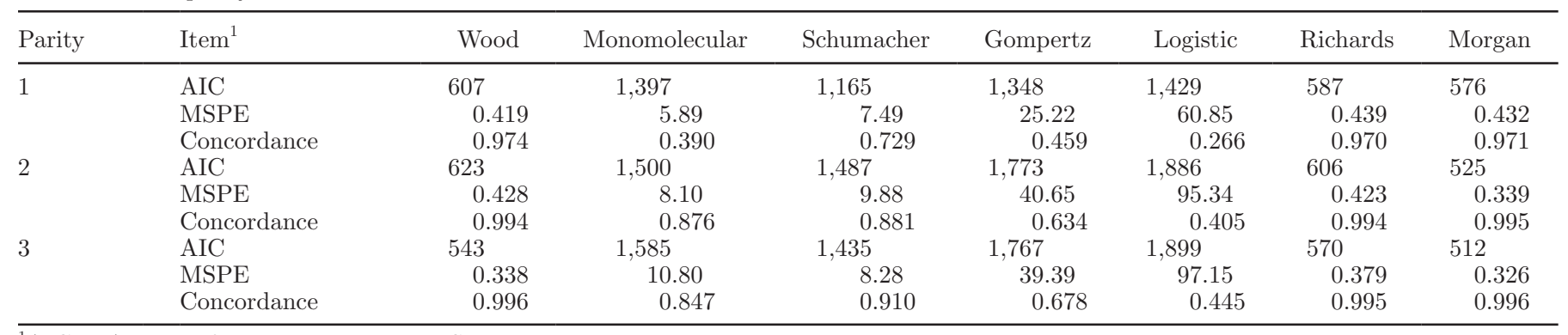

${ }^{1} \mathrm{AIC}=$ Akaike information criterion; MSPE $=$ mean square prediction error.

from onset of lactation at calving up to a maximum (peak of lactation occurring between wk 4 and 8 of lactation in dairy cattle), and a descending phase with a gradual decline in milk yield from peak to end of the lactation when the cow is dried off. This curve can be represented by parametric nonlinear equations whose parameters, individually or in combination, are amenable to mathematical and biological interpretation. Several mathematical functions have been used to fit this characteristic curve (Thornley and France, 2007; López, 2008), with the purpose of determining traits (such as DIM to peak, peak yield, total milk production per lactation) that summarize the information provided by a lactation curve built up from a limited number of milk yield recordings (test day milk yield). Some of the equations used are relatively complex, formulated from the combination (product) of 2 functions to represent both parts of the curve (Rook et al., 1993; Thornley and France, 2007; López, 2008). Some of the models have been derived from a mechanistic approach (Dijkstra et al., 1997; Pollott, 2000) with the purpose of not only predicting milk yield at any DIM but also of representing physiological and cellular processes occurring in the mammary gland. The statistical performance and suitability of the different lactation equations available in the literature has been extensively studied (Rook et al., 1993; Sherchand et al., 1995; Scott et al., 1996; Olori et al., 1999; Rekik et al., 2003; Val-Arreola et al., 2004; Macciotta et al., 2005; Silvestre et al., 2006; Dematawewa et al., 2007; Dijkstra et al., 2010; Steri et al., 2012).

The study described herein provides a novel insight into the modeling of lactation curves, proposing the use of classical growth functions to represent the cumulative milk production curve. Each daily milk yield at a given DIM is added to the sum of all the yields from calving to that particular DIM to calculate cumulative milk production. This results in a monotonically increasing curve displaying a characteristic sigmoidal shape, with an accelerating phase corresponding to early lactation when daily milk yield increases, and a decelerating phase in which the slope progressively decreases corresponding to the descending phase of the daily milk yield curve. Both are connected at the point of inflection where DIM shows the steepest slope, thus corresponding to peak of lactation and the slope to yield at peak (maximum yield during lactation). Total milk production per lactation is easily derived from this cumulative milk production curve as the value of the $y$-variable at a given DIM (at $305 \mathrm{~d}$ in standard

Table 7. Comparison of lactation traits (observed values and estimates derived from each model) when equations were fitted to average lactation curves for each parity

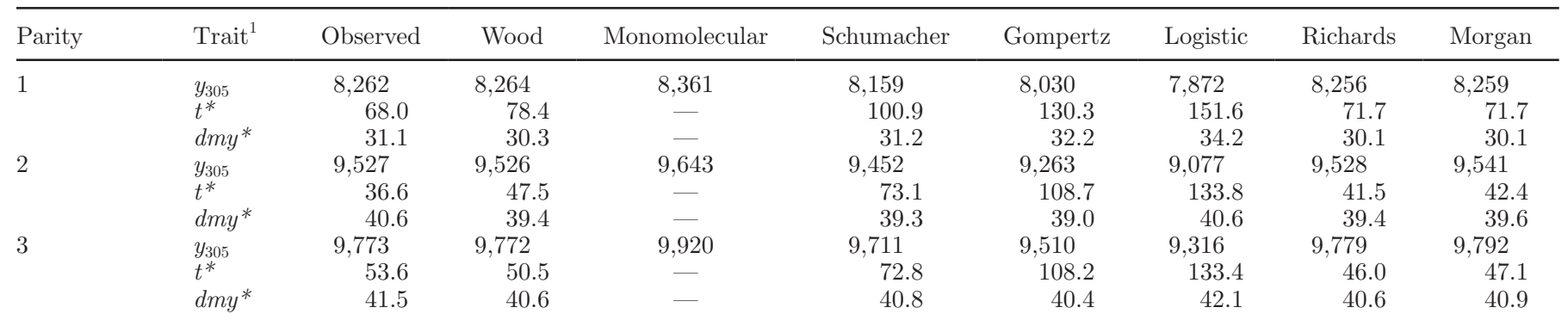

${ }^{1} y_{305}=$ lactation cumulative milk production $(\mathrm{kg})$ at $305 \mathrm{~d}$ of lactation; $t^{*}=$ day in milk at which peak is reached $(\mathrm{d}) ; d m y^{*}=$ daily milk yield $(\mathrm{kg} / \mathrm{d})$ at $t^{*}$. 
cattle lactations). This is in contrast with the classical lactation equations for which total milk production has to be calculated by integration (not always straightforward with some complex functions). The main weakness of this novel approach is that daily milk recordings from calving to the end of lactation are preferable, in contrast to the classical lactation equations that are usually fitted using a few test day milk yields (often monthly records). Modern milking systems in dairy farms record the individual yields at each milking, thus the novel approach can be easily implemented. The increased availability of records per individual lactation represents a challenge for the mathematical modeling of lactation curves in dairy cattle, shifting the emphasis of modelers toward more flexible functions (Macciotta et al., 2011).

The number of measurements, milking intervals, time interval between 2 consecutive recordings, and the DIM at which milk yield was recorded (particularly in early lactation and around the peak) are critical for accurate determination of lactation traits using conventional lactation curves (Nielsen et al., 2010; Macciotta et al., 2011; Wasike et al., 2011). Missing milk recordings (especially in early lactation) are a major handicap with classical lactation equations (Wasike et al., 2011; Adediran et al., 2012), whereas the novel approach presented herein would be affected to a lesser extent if a few (sporadic) records are missed. The cumulative milk production curve clearly shows a smoother trajectory (Figure 1) than that of the conventional lactation curve (Figure 2) and is less sensitive to the occurrence of outliers or abnormal recordings. These misleading data points can arise not only as a result of measurement errors, but because of biological disturbances in animal performance occurring when animals are challenged by some environmental distress (e.g., nutritional shortage, metabolic or infectious diseases) that constrains expression of their genetic potential (Codrea et al., 2011). It is important to detect such deviations from the underlying trend to identify the agent causing the distress and take corrective action, and this may be achieved from the analysis of daily milk yield records. However, these disturbances in the lactation curve can be highly influential when fitting classical lactation equations, whereas the fit of cumulative milk production curves would be almost negligibly affected by the occurrence of flawed measurements, demonstrating better adaptability to diverse data characteristics. Several studies have demonstrated that the lactation curve (daily milk yield vs. DIM) does not always follow the typical trajectory (standard curve) and have detected other curve shapes (reverse standard, continuously increasing or continuously decreasing patterns, other atypical shapes) that, in some cases, are not easily fitted by conventional lactation equations (Rekik and Gara, 2004; Macciotta et al., 2005; Silvestre et al., 2009). Some alternatives have been proposed to address this point. However, it is worth noting that cumulative milk production curves always follow a monotonically increasing pattern, regardless of the shape of the daily milk yield versus DIM curve, so that any difficulty arising from the existence of different shaped curves can be circumvented by fitting growth functions to cumulative curves, thus describing more precisely the underlying trend of the lactation curve relating to the productive potential of the animal with little interference by casual deviations from that trend.

Well-established growth functions can be satisfactorily fitted to cumulative milk production curves. In our study it was demonstrated that representative growth functions provided acceptable fits to observed lactation curves and accurate estimates of the required lactation traits. On the basis of the curve-fitting statistics examined, all the functions evaluated in the study showed suitable performance, considering the proportion of variance accounted for by the models was $>0.99$ when average curves by parity were fitted. The sigmoidal functions with a variable point of inflection (Richards and Morgan) provided the best fits and accurate estimates of lactation peak, yield at peak, and total milk production over the lactation. Interestingly, such findings on model accuracy are largely in line with the use of these functions to describe somatic or microbial growth (López et al., 2000, 2004; Darmani-Kuhi et al., 2010). The sigmoidal functions with a fixed point of inflection also provided an acceptable fit to the data and an accurate estimate of total milk production, but showed large variability in the estimates of DIM and yield at peak because the position of the point of inflection, which defines these traits, is imposed by the functional form of the equations. All the sigmoidal functions, except the logistic, accurately predicted total milk production per lactation (significantly correlated with the observed values) and adequately represented the expected relationships between lactation traits, in particular that between $d m y^{*}$ and $y_{305}$, confirming the validity of the estimates obtained. The monomolecular equation represents diminishing returns behavior, thus it is not suitable for providing estimates of the traits related to lactation peak. Regardless of this limitation, the function provided an accurate estimate of total milk production per lactation. Fathi-Nasri et al. (2008) reported good performance by the differentials of some growth equations compared with classical lactation models in fitting dairy cow lactation curves.

Fitting of growth functions to cumulative lactation curves was compared with that attained when the Wood equation was fitted to the traditional lactation 
curve (daily milk yield vs. DIM). Average lactation curves for first, second, and third parities were used for this comparison. A direct comparison was not possible because the Wood equation cannot be fitted to the cumulative milk production curve, which is a significant limitation of the model. The cumulative of the Wood equation is the lower incomplete gamma function. This is a special heteromorphic function and as such has no simple analytical solution. The cumulative of the Wood equation therefore does not lend itself to data fitting using standard nonlinear regression. The growth functions were fitted to cumulative lactation curves, and then daily milk yields at each DIM were calculated from the fitted cumulative milk production values estimated from each function for each curve. The model comparison (including the Wood equation) was based on the relationships between observed and fitted daily milk yield values at each DIM. Our results showed that Richards and Morgan functions provided a fit to the daily milk yield data comparing favorably with that achieved when the classical Wood equation was fitted to average lactation curves.

All the models included in our study showed a limitation in estimating milk yield at calving. This parameter cannot be estimated accurately with any of the models used to fit lactation curves, including the classical equation of Wood (1967) and other popular equations (Thornley and France, 2007). Nevertheless, this is not a key parameter in the characterization of lactation curves and it is largely influenced by pre- and peripartum physiological and environmental factors (Ingvartsen, 2006), thus showing much unexplained variation. Friggens et al. (1999) stated that cows can have appreciable milk yields at calving because the secretory potential of the mammary gland is well developed at parturition. Therefore, models with a zero intercept (at DIM $=0$, the function predicts zero yield) are less biologically acceptable. The growth functions used in the current study contain an intercept $\left(y_{0}\right)$, although the estimates obtained for this parameter when the functions were fitted to the curves were sometimes unrealistic (e.g., with the Gompertz and logistic equations).

It is important that models can discriminate between the effects of factors influencing the lactation curve. In this context, all the equations adequately represented the expected differences in the lactation curve among parities. These results are consistent with other reported studies (Wood, 1969; Friggens et al., 1999; Dijkstra et al., 2010), which demonstrated that the shape of the lactation curve was statistically different for cows of differing parities. The results of the current study are also in agreement with those of Dematawewa et al. (2007), who reported later peak DIM and greater milk yield at peak for first- compared with third-lactation cows.

Persistency of lactation $(p)$ refers to the ability of the cow to maintain yield after peak (Togashi and Lin, 2003; Kamidi, 2005). Persistency was calculated as the fractional rate of decline in milk yield after point of inflection of the cumulative milk production curve (representing the lactation peak) using the formulae shown in Table 1. Large differences were observed among models in the estimates of persistency. Several calculations have been proposed to assess this index (Gengler, 1996). It appears from the magnitude of $p$ determined using the different equations that the logistic and Gompertz underestimated persistency, whereas the monomolecular overestimated it. The magnitude of $p$ estimates from the Schumacher, Richards, and Morgan equations was similar to the relative rate of decline in cell numbers (or relative cell death rate) of 0.0046 per day reported by Pollott (2004). It was also well within the range of parameter values for the specific rate of death of secretory cells (0.002 to 0.008 per day) in the model of Dijkstra et al. (1997), which is based on mammary cell proliferation and death. In spite of the variability among models in the absolute values of $p$, all of them provided an acceptable relative comparison of $p$ between parities, showing how persistency decreased from parity 1 to 3 . First lactation cows tend to have flatter daily yield curves (i.e., greater persistency; Lennox et al., 1992; Sherchand et al., 1995; Scott et al., 1996; Dijkstra et al., 2010), whereas mature cows generally show greater yields at peak and a steeper decline (less persistency) toward the end of lactation than heifers (Table 2 and Figure 2). Wood (1968) suggested that older animals start their lactation at a higher level, but because the inhibiting effect of pregnancy occurs at about the same stage of lactation, whatever the level of production, the rate of decline is more rapid in older cows. Consistently no correlation was noted between persistency and milk production per lactation regardless of which function was used for their estimation, in agreement with Rekik et al. (2003). Other authors have considered persistency to be a reliable indicator of total milk production per lactation, based on a negative correlation between persistency and lactation production (Kamidi, 2005), probably because the production potential for cows with high persistency can only be expressed in extended lactations with a reduced rate of decline in yield after peak (Van Amburgh et al., 1997; Dekkers et al., 1998).

In conclusion, classical growth functions can be fitted to cumulative milk production curves, resulting in suitable statistical performance and accurate determination of lactation traits. This approach requires the recording 
of daily milk yields through all lactation, and therefore would be of special interest on farms with automatic recording systems. Flexible growth functions with a variable point of inflection (Richards and Morgan equations) showed best goodness-of-fit and provided accurate estimates of time to peak, peak yield, and persistency of lactation. Total milk yield of Holstein dairy cows in a 305-d lactation is predicted reliably when growth functions are fitted to lactation curves.

\section{ACKNOWLEDGMENTS}

Funding for this work was provided in part by the National Science and Engineering Research Council Canada Research Chairs and Discovery Programs (Ottawa).

\section{REFERENCES}

Adediran, S. A., D. A. Ratkowsky, D. J. Donaghy, and A. E. O. Malau-Aduli. 2012. Comparative evaluation of a new lactation curve model for pasture-based Holstein-Friesian dairy cows. J. Dairy Sci. 95:5344-5356.

Akaike, H. 1969. Fitting autoregressive models for prediction. Ann. Inst. Stat. Math. 21:243-247.

Bibby, J., and H. Toutenburg. 1977. Prediction and Improved Estimation in Linear Models. John Wiley \& Sons, London, UK.

Burnham, K. P., and D. R. Anderson. 2002. Model Selection and Multimodel Inference: A Practical Information-Theoretic Approach. 2nd ed. Springer-Verlag, New York, NY.

Codrea, M. C., S. Hojsgaard, and N. C. Friggens. 2011. Differential smoothing of time-series measurements to identify disturbances in performance and quantify animal response characteristics: An example using milk yield profiles in dairy cows. J. Anim. Sci. 89:3089-3098.

Darmani-Kuhi, H., T. Porter, S. López, E. Kebreab, A. B. Strathe, A. Dumas, J. Dijkstra, and J. France. 2010. A review of mathematical functions for the analysis of growth in poultry. World's Poult. Sci. J. 66:227-239.

Dekkers, J. C. M., J. H. Tem Hag, and A. Weersink. 1998. Economic aspects of persistency of lactation in dairy cattle. Livest. Prod. Sci. 53:237-252.

Dematawewa, C. M. B., R. E. Pearson, and P. M. VanRaden. 2007. Modeling extended lactations of Holsteins. J. Dairy Sci. 90:39243936.

Dijkstra, J., J. France, M. S. Dhanoa, J. A. Maas, M. D. Hanigan, A. J. Rook, and D. E. Beever. 1997. A model to describe growth patterns of the mammary gland during pregnancy and lactation. J. Dairy Sci. 80:2340-2354.

Dijkstra, J., S. López, A. Bannink, M. S. Dhanoa, E. Kebreab, N. E. Odongo, M. H. Fathi Nasri, U. K. Behera, D. Hernandez-Ferrer, and J. France. 2010. Evaluation of a mechanistic lactation model using cow, goat and sheep data. J. Agric. Sci. 148:249-262.

Fathi-Nasri, M. H., J. France, N. E. Odongo, S. López, A. Bannink, and E. Kebreab. 2008. Modelling the lactation curve of dairy cows using the differentials of growth functions. J. Agric. Sci. 146:633641.

Friggens, N. C., G. C. Emmans, and R. F. Veerkamp. 1999. On the use of simple ratios between lactation curve coefficients to describe parity effects on milk production. Livest. Prod. Sci. 62:1-13.

Gengler, N. 1996. Persistency of lactation yields: A review. Interbull Bull. 12:87-96.

Grossman, M., S. M. Hartz, and W. J. Koops. 1999. Persistency of lactation yield: A novel approach. J. Dairy Sci. 82:2192-2197.
Ingvartsen, K. L. 2006. Feeding- and management-related diseases in the transition cow. Physiological adaptations around calving and strategies to reduce feeding-related diseases. Anim. Feed Sci. Technol. 126:175-213.

Kamidi, R. E. 2005. A parametric measure of lactation persistency in dairy cattle. Livest. Prod. Sci. 96:141-148.

Lennox, S. D., E. A. Goodall, and C. S. Mayne. 1992. A mathematical model of the lactation curve of the dairy cow to incorporate metabolizable energy intake. Statistician 41:285-293.

Lin, L. I. K. 1989. A concordance correlation coefficient to evaluate reproducibility. Biometrics 45:255-268.

López, S. 2008. Non-linear functions in animal nutrition. Pages 47-88 in Mathematical Modeling in Animal Nutrition. J. France and E. Kebreab, ed. CAB International, Wallingford, UK.

López, S., J. France, W. J. J. Gerrits, M. S. Dhanoa, D. J. Humphries, and J. Dijkstra. 2000. A generalized Michaelis-Menten equation for the analysis of growth. J. Anim. Sci. 78:1816-1828.

López, S., M. Prieto, J. Dijkstra, M. S. Dhanoa, and J. France. 2004. Statistical evaluation of mathematical models for microbial growth. Int. J. Food Microbiol. 96:289-300.

Macciotta, N. P. P., C. Dimauro, S. P. G. Rassu, R. Steri, and G. Pulina. 2011. The mathematical description of lactation curves in dairy cattle. Ital. J. Anim. Sci. 10:e51 http://dx.doi.org/10.4081/ ijas.2011.e51.

Macciotta, N. P. P., D. Vicario, and A. Capplo-Borlino. 2005. Detection of different shapes of lactation curve for milk yield in dairy cattle by empirical mathematical models. J. Dairy Sci. 88:11781191.

Mitscherlich, E. A. 1909. Das Gesetz des Minimums und das Gesetz des abnehmenden Bodenertrages. Landwirschaftliche Jahrbücher $38: 537-552$.

Motulsky, H. J., and A. Christopoulos. 2003. Fitting Models to Biological Data Using Linear and Nonlinear Regression. A Practical Guide to Curve Fitting. GraphPad Software Inc., San Diego, CA.

NRC. 2001. Nutrient Requirements of Dairy Cattle. 7th rev. ed. Natl. Acad. Sci., Washington, DC.

Nielsen, P. P., G. Pettersson, K. M. Svennersten-Sjaunja, and L. Norell. 2010. Variation in daily milk yield calculations for dairy cows milked in an automatic milking system. J. Dairy Sci. 93:1069-1073.

Olori, V. E., S. Brotherstone, W. G. Hill, and B. J. McGuirk. 1999. Fit of standard models of the lactation curve to weekly records of milk production of cows in a single herd. Livest. Prod. Sci. 58:55-63.

Pollott, G. E. 2000. A biological approach to lactation curve analysis for milk yield. J. Dairy Sci. 83:2448-2458.

Pollott, G. E. 2004. Deconstructing milk yield and composition during lactation using biologically based lactation models. J. Dairy Sci. $87: 2375-2387$

Rekik, B., and A. B. Gara. 2004. Factors affecting the occurrence of atypical lactations for Holstein-Friesian cows. Livest. Prod. Sci. $87: 245-250$.

Rekik, B., A. B. Gara, M. B. Hamouda, and H. Hammami. 2003. Fitting lactation curves of dairy cattle in different types of herds in Tunisia. Livest. Prod. Sci. 83:309-315.

Rook, A. J., J. France, and M. S. Dhanoa. 1993. On the mathematical description of lactation curves. J. Agric. Sci. 121:97-102.

Scott, T. A., B. Yandell, L. Zepeda, R. D. Shaver, and T. R. Smith. 1996. Use of lactation curves for analyzing of milk production data. J. Dairy Sci. 79:1885-1894.

Sherchand, L., R. W. McNew, D. W. Kellog, and Z. B. Johnson. 1995. Selection of a mathematical model to generate lactation curves using daily milk yields of Holstein cows. J. Dairy Sci. 78:2507-2513.

Silvestre, A. M., A. M. Martins, V. A. Santos, M. M. Ginja, and J. A. Colaco. 2009. Lactation curves for milk, fat and protein in dairy cows: A full approach. Livest. Sci. 122:308-313.

Silvestre, A. M., F. Petim-Batista, and J. Colaco. 2006. The accuracy of seven mathematical functions in modeling dairy cattle lactation curves based on test-day records from varying sample schemes. J. Dairy Sci. 89:1813-1821. 
Steri, R., C. Dimauro, F. Canavesi, E. L. Nicolazzi, and N. P. P. Macciotta. 2012. Analysis of lactation shapes in extended lactations. Animal 6:1572-1582.

Thornley, J. H. M., and J. France. 2007. Mathematical Models in Agriculture. 2nd ed. CAB International, Wallingford, UK.

Togashi, K., and C. Y. Lin. 2003. Modifying the lactation curve to improve lactation milk and persistency. J. Dairy Sci. 86:1487-1493.

Val-Arreola, D., E. Kebreab, J. Dijkstra, and J. France. 2004. Study of the lactation curve in dairy cattle on farms in Central Mexico. J. Dairy Sci. 87:3789-3799.

Van Amburgh, M. E., D. M. Galton, D. E. Bauman, and R. W. Everett. 1997. Management and economics of extended calving intervals with use of bovine somatotropin. Livest. Prod. Sci. 50:15-28.

Wasike, C. B., A. K. Kahi, and K. J. Peters. 2011. Modelling of lactation curves of dairy cows based on monthly test day milk yield records under inconsistent milk recording scenarios. Animal 5:1780-1790.

Wood, P. D. P. 1967. Algebraic model of the lactation curve in cattle. Nature 216:164-165.

Wood, P. D. P. 1968. Factors affecting persistency of lactation in cattle. Nature 218:894.

Wood, P. D. P. 1969. Factors affecting the shape of the lactation curve in cattle. Anim. Prod. 11:307-316.

Wood, P. D. P. 1970. A note on the repeatability of parameters of the lactation curve in cattle. Anim. Prod. 12:535-538.

Wood, P. D. P. 1980. Breed variations in the shape of the lactation curve of cattle and their implications for efficiency. Anim. Prod. $31: 133-141$ 